\title{
A leitura a partir da fenomenologia e semiótica de C. S. Peirce
}

Reading according to the phenomenology and semiotics of C. S. Peirce

https://doi.org/10.34112/2317-0972a2017V35n70p133-145

\section{André Luiz Ming Garcia ${ }^{1}$}

RESUMO: No presente artigo, procura-se apresentar a fenomenologia e a semiótica de Charles Sanders Peirce, através do estudo de suas três categorias fenomenológicas, a fim de ajudar-nos a entender uma proposta de leitura de signos estéticos como um processo trifásico, que se inicia na leitura emotiva ou de sensações e impressões, correspondente à primeiridade, perpassando a leitura de comparações e choques e atingindo, por fim, a leitura crítica e analítica das redes de sentidos e representações que podem dar origem a obras e textos de natureza verbal, visual ou verbovisual (assumindo-se aqui, portanto, uma versão pansemiótica de texto).

Palavras-chave: Leitura; Charles Sanders Peirce; fenomenologia.

ABSTRACT: In the present article, we present the phenomenology and the semiotics of Charles Sanders Peirce, through the study of his three phenomenological categories, in order to help us understand the process of reading aesthetic signs as a three-phase process, that begins with reading as characterized by emotions or impressions, which corresponds to the firstness, going to reading as comparisons and shocks, typical for secondness, and finally reaching the critical and analytical reading of the networks of senses and representations

1. Universidade de São Paulo, São Paulo, SP, Brasil. 
that may lead to works and texts of a verbal, visual or verbovisual nature, in the fields of thirdness (assuming here, therefore, a pansemiotic version of a text).

Keywords: Reading; Charles Sanders Peirce; phenomenology.

\section{INTRODUÇão}

No presente trabalho, pretende-se apresentar um estudo das três categorias fenomenológicas de Charles Sanders Peirce, o pai da semiótica triádica de extração norte-americana, que nos ensinam a ver que a leitura de textos estéticos, sejam eles verbais, verbovisuais ou visuais, pode ser dividida em três fases principais. A primeira delas, correspondente à primeiridade, é aquela em que o leitor é invadido por impressões e sensações a respeito da obra. Na segunda delas, correspondente à secundidade, categoria da alteridade, do contraste e do choque, ocorre a leitura de choque ou de comparação com outras versões, paráfrases, paródias e adaptações multimodais da obra em questão. Já na terceira fase, correspondente à terceiridade, ocorre a leitura propriamente crítica e analítica da obra.

A aplicação das categorias peircianas à leitura trifásica se presta à análise das três fases de fruição de quaisquer signos estéticos ou de quaisquer tipos de leitura. A contribuição deste artigo consiste em uma aplicação das categorias peircianas ao ato de leitura, indo, portanto, além de uma mera enumeração da tríade de categorias peircianas.

Apresentamos, no final, uma proposta de como poderia ser feita uma leitura trifásica da história de Chapeuzinho Vermelho, pois trata-se de uma obra bastante parafraseada, parodiada, adaptada a outras mídias e gamificada.

\section{FUndamentaÇÃo TEÓRICA: A FANEROSCOPIA E AS TRÊS}

CATEGORIAS ${ }^{2}$

Um dos principais interesses de Peirce consistia em elaborar uma fenomenologia, ou ciência da classificação dos fenômenos da mente e do mundo externo a

2. Para maiores detalhes, ver, em Peirce (1931), "Sobre uma nova lista de categorias" (CP 1.545-567), de 1867, e "Um, dois, três: categorias fundamentais do pensamento e da natureza” (CP 1.369-384), de 1885. Sobre o espírito anticartesiano do pensamento de Peirce, manifesto já na elaboração das categorias, ver Santaella (2004). Observação: CP é uma indicação bibliográfica que segue o padrão internacional de citações de textos de Peirce. “CP” corresponde a Collected Papers (PEIRCE, 1931) e os números correspondem ao volume e parágrafo. 
ela ("universo da aparência3", cf. SILVEIRA, 2007, p. 39) em um número limitado e irredutível de categorias gerais e universais. Sendo esse número de categorias irredutível, Peirce afirma que "se [...] considerarmos um fato quádruplo, é fácil exprimi-lo como sendo um composto de dois fatos triplos. [...] Todos os fatos plurais podem ser assim reduzidos a fatos triplos" (PEIRCE, 2012, p. 11, \371).

Segundo Peirce, "a lista de categorias [...] é uma tábula de concepções extraída da análise lógica do pensamento, aplicáveis ao ser” (PEIRCE, 1983, p. 88, \300), "oferecendo as bases para uma semiótica anti-racionalista, antiverbalista e radicalmente original” (SANTAELLA, 2002b, p. 11).

Sobre suas categorias em comparação às de outros filósofos que o precederam e que ele estudou, vale afirmar que Peirce elaborou sua lista a partir do reconhecimento de padrões triádicos nos esquemas categoriais de Kant e Hegel.

Não se pode esquecer, entretanto, da aspectualização que caracteriza e define a semiose e a acepção do fenômeno sob a perspectiva peirciana: uma categoria pode prevalecer em um dado fenômeno, mas todas estão presentes em todos os fenômenos. A terceiridade, por exemplo, implica e contém a secundidade e esta implica e contém a primeiridade. Além disso, a mudança do aspecto (perspectiva ou contexto), a partir do qual se entende o fenômeno, garante que ele possa ser encarado como correspondente a qualquer uma das três categorias ou a uma mistura delas.

Peirce utilizava muitos neologismos para diferenciar seus conceitos dos de outros sistemas filosóficos. Assim, denominou sua fenomenologia ideoscopia ou faneroscopia, do grego phaneron, manifestação, aparência. A fenomenologia seria, segundo Peirce, a primeira das três grandes divisões da filosofia, seguida das ciências normativas (estética, ética e semiótica ou lógica) e da metafísica, e visaria a possibilitar "a mais radical análise de todas as experiências possíveis" (SANTAELLA, 1985, p. 36), sendo a "base fundamental para qualquer ciência" (SANTAELLA, 1985, p. 38) e, sem lugar à dúvida, a base da arquitetura filosófica peirciana. Peirce começou a se ocupar com as categorias em 1867, em "Sobre uma nova lista das categorias", texto conhecido simplesmente como "Nova lista" (PEIRCE, 1931), e cunhou o termo faneroscopia por volta de 1902. Em 1885, em "Um, dois, três: categorias fundamentais do pensamento e da natureza” (PEIRCE, 1931), estendeu a semiose para o domínio da natureza.

3. Silveira (2007, p. 39) também se refere à fenomenologia como "ciência da aparência em geral" com a finalidade de "fundamentar toda a conduta dos seres inteligentes”. A fenomenologia, para o autor, "proporá o quadro categorial capaz de expressar a aparência em sua irrestrita universalidade”. 
Fênomeno, para Peirce, seria tudo aquilo que aparece 4 à mente, "de algum modo e em qualquer sentido"s (PEIRCE, 2012, p. 41), trate-se de algo real ou imaginário ${ }^{6}$, de origem interna ou externa. Por esse motivo, pode-se afirmar que todo tipo de fenômeno consiste em signos agindo ou sendo signos. Um fenômeno ou um signo são ou podem ser, assim, qualquer coisa.

Sobre a interdependência das categorias, Peirce explana:

[...] as categorias não podem ser dissociadas umas das outras na imaginação (nem das outras ideias). A categoria do primeiro pode ser prescindida do segundo e terceiro, e o segundo prescindido do terceiro. Mas o segundo não pode ser prescindido do primeiro, nem o terceiro do segundo. (PEIRCE, 2012, p. 97).

Tecidas essas considerações inicias sobre a fenomenologia de Peirce, em seguida são elencadas as suas categorias, por ele denominadas ceno-pitagóricas.

\subsection{A PRIMEIRIDADE}

A primeiridade é a categoria daquilo "que é o que é sem referência a qualquer outra coisa dentro dele, ou fora dele, independentemente de toda força e de toda razão" (PEIRCE, 2012, p. 24, $\$ 85$ ). É a categoria da mônada, da talidade, da qualidade de sentimento, "do sentimento sem reflexão, da mera possibilidade, da liberdade 7 , do imediato, da qualidade ainda não distinguida e da independência” (NÖTH, 2005, p. 63). Ibri (2001) acrescenta a esses elementos a vida, a novidade e a ausência de alteridade. Santaella adiciona a esse mosaico o frescor, o acaso (tiquismo), "originalidade irresponsável e livre, variação espontânea", um "estado-quase” (SANTAELLA, 1985, p. 52-7), a indefinição (SANTAELLA, 1994, p. 115), o irrepetível (SANTAELLA, 1994, p. 116). O que está na mente no presente instante é anterior a qualquer análise, "nenhuma outra coisa senão pura qualidade de ser e de sentir" (SANTAELLA, 1985, p. 57), "o que há de mais indefinível na vida e no mundo" (SANTAELLA, 1994, p. 115). Trata-se da "qualidade em si mesma, que é

4. Assim, Silveira (2007, p. 41) se refere à fenomenologia como uma "ciência da aparência em geral".

5. O que reafirma a aspectualização.

6. Assim, Nöth (2005, p. 69) afirma que "a filosofia semiótica de Peirce ultrapassou a dicotomia entre o idealismo e o realismo".

7. Santaella (1985, p. 67) especifica que essa seria a liberdade "em relação a qualquer elemento segundo". 
um poder-ser não necessariamente realizado" não sendo uma ocorrência (PEIRCE, 1983, p. 88-9, \$ 304).

Dadas essas características, pode-se notar que a primeiridade é uma categoria de difícil ou impossível captura e de complexa definição, um conceito profundamente abstrato, ainda que Peirce afirme que a primeiridade em si não pressupõe abstração e não é, por isso, abstrata (PEIRCE, 1983, p. 88-9, \$302). O caráter vago e de difícil captura do elemento primeiro fica claro em Peirce. Para ele, pertence à primeiridade

[...] o que poderia surgir como existindo no instante presente se estivesse completamente separado do passado e do futuro [...]. Nada é mais oculto que o presente absoluto [...]. Sem a possibilidade de ação, falar em binaridade seria proferir palavras sem significado. [Um] sentir [que] poderia ter seu tom próprio [...]. Não poderia nem mesmo haver um grau de nitidez desse sentir [...]. O mundo seria reduzido a uma qualidade de sentimento não analisado. Posso denominar sua forma Primeiridade, Oriência ou Originalidade. (PEIRCE, 2012, p. 24, $\$ 85$ ).

A primeiridade fica caracterizada, assim, como a categoria daquilo que, em seu frescor, é prévio a qualquer análise ou comparação, sempre uma possibilidade em aberto ou infinitas possibilidades em seu estado de latência, de talvez vir a ser. É a "base primeira de toda realidade, sendo pressuposta nos confrontos existenciais, assim como em todo contínuo e em toda generalização" (SILVEIRA, 2007, p. 42), ou seja, a primeiridade está encapsulada ou pressuposta na secundidade e na terceiridade, porque as categorias se pressupõem e se constituem umas a partir das outras, em ordem decrescente, e se degeneram, com "redução de seu estado ontológico"'. A primeiridade, no caso, não pode sofrer degeneração, enquanto a terceiridade pode degenerar-se em até dois graus, dando origem à secundidade e à primeiridade, e a secundidade, em um, dando origem à primeiridade.

Ainda sobre a primeiridade, esta seria a categoria de um "estado meramente contemplativo", (...) "um estado de consciência absolutamente mergulhado no presente", "um hiato no tempo da consciência" (IBRI, 2001, p. 71) ou, pode-se dizer, um sentir-se geral de cada instante do curso da vida. Não possui unidade nem partes (SANTAELLA, 1985). Apesar de seu caráter imediato e anterior a qualquer presentificação ou mediação, as nossas qualidades de sentimento são já "tradução,

8. Cf. Romanini (2009), Minute Semeiotic. 
finíssima película de mediação entre nós e os fenômenos. Qualidade de sentir é o modo mais imediato, mas já imperceptivelmente medializado de nosso estar no mundo" (SANTAELLA, 1985). Trata-se, portanto, de quase-signos, de signos que não possuem ou não exercitam a faculdade de representar outra coisa ou que, se algo representam, é a si mesmos.

Porque não contempla a sucessão do e no tempo, a primeiridade é também a categoria do pré-verbal, do irracional, do inanalisável, do indescritível, do não-cognitivo, do não-intelectual (PIGNATARI, 1979).

\subsection{A SECUNDIDADE OU SEGUNDIDADE}

Dando sequência ao quadro categorial de Peirce, temos a secundidade, categoria que "começa quando um fenômeno primeiro é relacionado a um fenômeno segundo qualquer" (NÖTH, 2005, p. 64). Para o pensador norte-americano, "a segunda categoria é o traço seguinte comum a tudo que é presente à consciência - é o elemento de "conflito"' (PEIRCE, 1983, p. 90, \$ 322 ).

A secundidade é a categoria da díada e da binaridade, "da ação, do fato, da realidade e da experiência no tempo e no espaço" (PEIRCE, 1983, p. 90, $\$ 322$ ), incluindo ainda o ego (individualidade) e o não-ego (alteridade), a dependência, a resistência, luta e confronto, a interrupção, a descontinuidade, a intrusão, a segmentação, o registro do passado, a reação e a causalidade. É a categoria do querer e da volição (PIGNATARI, 1979), e também a categoria dos signos dêiticos. Segundo Silveira (2007), a secundidade seria também a categoria da fatualidade, da negação e da existência. É próprio da secundidade o forçar-se de um fenômeno sobre nossa consciência e, assim, também o é a experiência.

Assim, se a primeiridade era a categoria do presente imediato e não analisado, a secundidade mostra ser a categoria do passado e da experiência ocorrida - por sua vez, perfeitamente analisáveis:

[...] a experiência é esse in praeterito. [...] Algum fato existe. [...] Qual é, então, o fato que se apresenta a você? Pergunte-se a si mesmo: é o passado. Um fato é um fait accompli; o seu esse está no praeterito. $\mathrm{O}$ passado compele o presente, em alguma medida, no mínimo. [...] Sua força é a força bruta. (PEIRCE, 2012, p. 23). 
Afirma Santaella (1985, p. 62-3): "O simples fato de estarmos vivos, existindo, significa, a todo momento, consciência reagindo em relação ao mundo. Existir é sentir a ação de fatos externos resistindo à nossa vontade".

Santaella diferencia a qualidade de sentimento que caracteriza a primeiridade ("puro sentir, antes de ser percebido como existindo num eu"), de uma sensação que nos invade, "ação de um sentimento sobre nós" e "nossa reação específica, comoção do eu para com o estímulo", já próprias da secundidade. As sensações turvas e quase indescritíveis que caracterizam a primeiridade, se singularizadas, recortadas, passam a ser analisáveis, e se tornam fenômenos segundos como tudo aquilo que é singular.

Sobre a questão da força bruta, da resistência e da ação e reação, bem como da volição, próprias da secundidade, Peirce afirma:

Não importa quão boa possa ser a justificativa que temos para um ato da vontade, quando passamos para sua execução a razão não faz parte do trabalho: o que se tem é a ação bruta. Não podemos fazer esforço algum onde não sentimos resistência alguma, nenhuma reação. [...] Há uma binaridade na ideia de força bruta; é seu principal ingrediente. Pois a ideia de força bruta é pouco mais do que a reação, e esta é pura binaridade. (PEIRCE, 2012, p. 23, $\$ 84$ ).

Não há esforço sem resistência equivalente, e a resistência implica o esforço ao qual resiste. Ação e reação são equivalentes. (PEIRCE, 1983, p. 18, \$ 45).

A secundidade pressupõe a primeiridade e se constitui a partir dela. Além disso, a secundidade genuína se degenera, com perda de complexidade e redução de estado ontológico (ROMANINI, 2009). A secundidade pode degenerar-se em um grau, rumo à primeiridade, gerando a primeiridade da secundidade que, segundo o estudioso, "corresponde à existência de algo em si mesmo, sentimento de alteridade que invade uma mente. Como existência pura, é mera flutuação, instabilidade e irritação" (ROMANINI, 2009, n.p.). Demonstrando que a secundidade encontra-se um passo atrás da terceiridade, fala-nos Peirce: "A brutalidade consistirá na ausência de qualquer razão, regularidade ou norma que poderia tomar parte na ação como elemento terceiro ou mediador" (PEIRCE, 2012, p. 23).

$\mathrm{E}$ é desse elemento terceiro ou mediador que trata a próxima e última categoria. 


\subsection{A TERCEIRIDADE}

Esta categoria completa a lógica ternária de Peirce. A terceiridade é a categoria "de mediação entre a primeira e a segunda" (IBRI, 2001, p. 73), "que relaciona um fenômeno segundo a um terceiro" (NÖTH, 2005, p. 64).É a categoria da continuidade (sinequismo), do hábito, da lei, da norma, da síntese, do geral e da generalização, da aprendizagem, da comunicação, sendo a categoria dos signos, da significação e da representação e, assim, da semiose e da semiótica, bem como da(s) linguagem(s). Resume Peirce: "algumas das ideias de grande importância para a ciência e a filosofia onde a Terceiridade predomina são generalidade, infinidade, continuidade, difusão, crescimento e inteligência” (PEIRCE, 1983, p. 93, \$340).

Ainda segundo o filósofo, "toda relação triádica genuína envolve significado" (PEIRCE, 1983, p. 93, $\$ 345$ ). E, por extensão, a representação. Vejamos: "A ideia mais simples de Terceiridade dotada de interesse filosófico é a ideia de um signo, ou representação. Um signo 'representa' algo para a ideia que provoca ou modifica" (PEIRCE, 1983, p. 93, $\$ 339$ ). Assim, segundo Santaella (1985, p. 67), a terceiridade "aproxima um primeiro e um segundo numa síntese intelectual, [correspondendo] à camada da inteligibilidade, ou pensamento em signos, através da qual representamos e interpretamos o mundo". Segundo Peirce, a terceiridade seria "o modo de ser que consiste no fato de fatos futuros de secundidade virem a adquirir caráter geral" (CP 1.26 em PEIRCE, 1931). A terceiridade supõe a primeiridade e a secundidade, que nela estão contidas (SILVEIRA, 2007).

Ao passo que a primeiridade está, como vimos, associada ao presente imediato, e a secundidade ao passado recortável e analisável, a terceiridade, por sua vez, pressupõe a implicação de eventos futuros como efeito de lei. A respeito, afirma Peirce: "A lei da natureza possuiria uma espécie de esse in futuro. Isto é, possui uma realidade que consiste em que os eventos acontecerão de acordo com a formulação dessas leis" (PEIRCE, 1983, p. 20, $\$ 48$ ).

\section{Uma aplicação da faneroscopia de Peirce: aproximação e FRUIÇÃO TRIFÁSICA E EM CONTINUUM DE OBRA LITERÁRIA}

Como observamos, as três categorias se pressupõem em ordem decrescente: a terceiridade incorpora a secundidade, que incorpora a primeiridade. Desse modo, tanto a secundidade quanto a primeiridade estão contidas na terceiridade, a mais 
complexa das categorias. Vimos também que a primeiridade, do ponto de vista lógico, é a menos complexa das três categorias e que a terceiridade é a mais complexa de todas elas. Uma qualidade qualquer, não analisada, não recortada e não singularizada, correspondendo à primeiridade, poderia vir a se tornar atributo de um ser singular (fenômeno segundo), estando nele contida. Essa mesma qualidade poderia passar, por força de hábito, regra ou lei, a ser encontrada em outros indivíduos de um dado grupo, por meio de uma generalização, de modo que essa lei (terceira) envolveria os entes individuais (segundos) que, por sua vez, envolveriam as qualidades (primeiras).

Importante para este trabalho é observar como a fruição de um fenômeno pode ir de uma aproximação menos complexa, correspondente à primeiridade, a uma mais complexa ${ }^{9}$, pertencente à terceiridade, perpassando, logicamente, a secundidade.

Cabe retomar, aqui, o fato de que o pensador norte-americano considerou três "faculdades" que devemos reunir para entender um fenômeno, ou três modos como os fenômenos aparecem-nos na experiência: primeiramente, trata-se de perceber o fenômeno sem qualquer traço de interpretação; em segundo lugar, de encará-lo e analisá-lo diretamente e, em terceiro lugar, de chegar a uma compreensão do fenômeno examinado que identifique as leis ou generalidades que o regem. Fica evidente, assim, que cada uma dessas três fases de apreensão do fenômeno corresponde a uma categoria ceno-pitagórica. À primeiridade corresponde o permitir-se contemplar o fenômeno sem interpretá-lo, uma vez que a interpretação, alicerçada em implicações de entendimento de representações e significações, bastante complexa, pertenceria à terceiridade. Trata-se da mera contemplação de características e qualidades do fenômeno e, por que não, das impressões e sensações que ele emana ou suscita a quem o pretende fruir. Em seguida, com o exemplo peirciano da atitude firme do bulldog diante daquilo que encara, surge a análise daquilo que se vê. $\mathrm{O}$ fenômeno resiste, como força bruta, singularizado, independente do que se possa pensar dele, e o analista impõe sobre ele a força de sua análise discriminatória de características. Está-se, aqui, no âmbito da secundidade. Finalmente, ocorre a análise em toda sua complexidade terceira, com a geração de uma fórmula que dê conta de possibilitar a compreensão geral e mais completa do fenômeno. Desse modo, vemos a recepção do fenômeno perpassando um continuum analítico que vai da primeiridade à terceiridade, atravessando a secundidade. Malgrado essas observações,

9. Afirma Santaella (2002a, p. 101 - negrito nosso): "Para Peirce, um sistema filosófico deve ser capaz de dar conta dos seguintes traços distintivos do universo observável: crescimento e desenvolvimento de complexidade; variedade; regularidade, isto é, leis da natureza; por fim, consciência ou sentimento”. 
é importante ressaltar o fato de que todo entendimento e toda cognição constituem elementos próprios da terceiridade.

Com base nas três fases de apreensão do fenômeno, propostas por Peirce, propõe-se, a seguir, o esquema de fruição trifásico de signos estéticos, literários e/ou artísticos:

\begin{tabular}{|l|}
\hline o. O pré-domínio da possibilidade; \\
\hline Transição o/1: domínio das impressões \\
\hline 1. A leitura emotiva ou leitura de impressões; \\
\hline Transição 1/2: instâncias da comparação \\
\hline 2. A leitura comparativa ou leitura de choque, observação e percepção; \\
\hline Transição $2 / 3$ : formulações de análise \\
\hline $\begin{array}{l}\text { 3. A leitura multissemiótica em palavra-imagem- } \text { design }^{10} \text { ou a apreensão mais completa, } \\
\text { complexa e racional do objeto. }\end{array}$ \\
\hline
\end{tabular}

Tabela 1: As três fases de fruição do signo estético e as fases intermediárias

Observa-se, nessa tabela, três fases em continuum de apreensão, fruição ou reflexão do objeto artístico e literário, com essas fases sendo precedidas por uma pré-fase (o), correspondente ao mundo de possibilidades de interpretação que é intrínseco à obra de arte em estado de latência ou prévia a qualquer leitura ou processo decodificador. Trata-se da obra de arte em espera, como plena possibilidade de interpretação. Primeiramente, no que denominou-se fase zero da fruição de um texto ou objeto estético, levaram-se em conta as questões relativas à fruição das obras correspondentes à primeiridade. Trata-se do momento em que a obra de arte repousa em latência à espera de um intérprete ou inteligência interpretadora que virá, como coautor da obra, a transformá-las em casos e possibilidades concretas de fruição. Toda obra em repouso é, assim, uma obra repleta de remas, categoria de signos de primeiridade em relação com o interpretante (pensamento ou sensação que o signo impinge ao intérprete), caracterizada como um conjunto de possibilidades não realizadas de interpretação.

$\mathrm{Na}$ fase 1 da recepção ou leitura do fenômeno, tem-se o domínio das impressões e sensações que a obra suscita no leitor. Aqui está a primeiridade, devido ao predomínio das sensações, elementos que integram essa categoria, e é aqui que se manifesta o critério gosto na avaliação da obra lida: nesse momento, o leitor sente impressões e sensações a respeito da obra à qual foi exposto e começa a decidir se está gostando ou não daquilo que lê, ouve ou vê.

10. Conceito palavra-imagem-design com origem e base em Abreu (2013). 
Em segundo lugar, e já no âmbito da secundidade, ocorre o que denominamos leitura comparativa ou de choque, que é o momento em que o leitor tece comparações entre a obra que está fruindo e outras obras de algum modo semelhantes ou até mesmo derivadas do texto que está lendo. Imaginemos o exemplo da leitura de um livro ilustrado do conto de fadas (LICF) Chapeuzinho Vermelho. Tantas são as adaptações e versões, além de paródias e paráfrases desse conto, que é muito pouco provável que o leitor de um dado livro ilustrado não o associe a outros desse mesmo conto ou a paródias (como Chapeuzinho Amarelo, de Chico Buarque com ilustrações de Ziraldo ou de Berlendis (2012), Nove Chapeuzinhos, de Flávio de Souza (2014), Chapeuzinho Vermelho e o lobo guará, de Ângelo Machado (1988), para citar apenas alguns dos exemplos brasileiros mais proeminentes), além de adaptações multimodais do conto, sua gamificação etc. A comparação, em si, é associada por Santaella (1992, p. 194) à primeiridade, devido ao fato de consistir em um tipo de tratamento de textos em que são buscadas e evidenciadas suas qualidades. Entretanto, é fundamental considerar a comparação uma fase intermediária entre a primeiridade e a secundidade, já que contém o elemento do choque, do contraste e da alteridade que tanto caracterizam a segunda das categorias. Trata-se, assim, muito mais de uma leitura caracterizada pelo choque, pela quebra de expectativas, pela alteridade, pelo contraste causado pelos pensamentos concretos que invadem nossa mente durante a leitura de uma obra tão parodiada, parafraseada e multimodalmente adaptada quanto Chapeuzinho Vermelho.

Assim, entende-se que a análise consiste numa transição entre a secundidade e a terceiridade, de modo que as partes do continuum da leitura trifásica de uma obra deem lugar umas às outras de forma gradual. Na terceira fase da leitura de uma obra artística ou literária, como Chapeuzinho Vermelho, tem-se o que podemos denominar uma leitura efetivamente racional e analítica, com a depreensão dos signos que estão estruturados em três eixos de linguagem: os registros verbais, os registros visuais e o design ou projeto gráfico, todos embebidos de sentidos e inter-relacionados na construção desse tipo de obra.

Faz-se relevante, entretanto, frisar que o continuum trifásico de leitura e fruição de textos consiste em um ideal, uma possibilidade, sendo que é possível que leitores específicos abdiquem de alguma dessas fases em seu processo de fruição, invertam sua ordem ou limitem-se à leitura emotiva, o que consiste, inclusive, em uma possibilidade contemplada pelo próprio Peirce. A continuidade, como nos mostram as reflexões sobre o sinequismo, pode ser e frequentemente é interrompida por 
diversos fatores, como a ação bruta do acaso. Apesar disso, acreditamos, seguindo a lógica peirciana que, no mais das vezes, na realidade, a leitura primeira ou emotiva está contida na leitura comparativa, de choque e sensorial, bem como essas duas formas de leitura estão contidas na terceira e mais complexa, a leitura racional, de modo que esse continuum teoricamente delineado se torne, na prática de fruição, uma grande mistura de sensação, análise, comparação, raciocínio, percepção etc.

\section{CONSIDERAÇÕeS FINAIS}

No presente texto, pretendeu-se apresentar as três categorias ceno-pitagóricas de Peirce, que consistem nas pilastras de sua filosofia, ou seja, a sua fenomenologia ou faneroscopia. De acordo com conhecimentos acumulados sobre as categorias criadas e definidas por Peirce, apresentamos as associações propostas por ele. A primeira delas às sensações ou qualidades de sentimento; a segunda à individualização, singularização, ao choque e ao contraste, bem como às relações de alteridade; a terceira, por sua vez, à compreensão crítica e racional de fenômenos. Desse modo, e considerando que os fenômenos podem crescer em complexidade com o avanço das categorias, propusemos uma aplicação da faneroscopia (fenomenologia) peirciana à leitura de um texto (verbal, verbovisual ou visual), que atravessa três fases distintas, partindo da leitura emotiva para a leitura de choque e a leitura crítica e analítica dos textos em questão, perfazendo assim, com aumento de complexidade na passagem das categorias, a primeiridade, a secundidade e a terceiridade.

Entendendo o texto como signo de possibilidade (primeiridade), provocando emoções em um primeiro momento da leitura; explicitando o choque em segunda etapa, na qual ocorrem comparações entre a obra lida e outras de suas possíveis versões; e aprofundando a terceira fase, a mais cognitiva e que se caracteriza pela decodificação os signos que compõem a obra, deixamos mais evidentes a complexidade e as possibilidades do ato de ler.

\section{REFERÊNCIAS}

ABREU, A. O texto potencial no sistema ecológico do livro ilustrado infantil: palavra-imagem-design. [1913] Dissertação (Mestrado em Literatura e Crítica Literária)- Pontifícia Universidade Católica de São Paulo, São Paulo, 2013.

BUARQUE, C.; Ziraldo. Chapeuzinho amarelo. São Paulo: Autêntica, 2012. 
IBRI, I. A. Ser e aparecer na filosofia de Peirce: o estatuto da fenomenologia. Cognitio (São Paulo), v. 2, p. 67-75, 2001.

MACHADO, Â. Chapeuzinho Vermelho e o lobo guará. São Paulo: Melhoramentos, 1988. NÖTH, W. Panorama da semiótica: de Platão a Peirce. 4. ed. São Paulo: Annablume, 2005.

PEIRCE, C. S. Os pensadores (Peirce/Frege). Trad. Armando Mora D’Oliveira e Sérgio Pomerangblum. São Paulo: Abril, 1983. . Semiótica. 4. ed. Trad. José Teixeira Coelho Neto. São Paulo: Perspectiva, 2012. . Collected Papers of Charles Sanders Peirce. Cambridge, MA: Harvard University Press, 1931. vol. 1-6.

PIGNATARI, D. Semiótica \& Literatura. São Paulo: Cortez, 1979.

ROMANINI, V. Minute Semeiotic. 2009. Disponível em: <http://www.minutesemeiotic.org/>.

Acesso em: 23 jul. 2017.

SANTAELLA, L. A assinatura das coisas: Peirce e a literatura. Rio de Janeiro: Imago, 1992. . Estética de Platão a Peirce. São Paulo: Experimento, 1994. . O que é semiótica. 3. ed. São Paulo: Brasiliense, 1985. . A teoria geral dos signos: como as linguagens significam as coisas. São Paulo: Cengage

Learning, 2000 . . Os significados pragmáticos da mente e sinequismo em Peirce. Cognitio, São Paulo, n. 3 ,

nov. 2002a, p. 97-106. . Semiótica aplicada. São Paulo: Cengage Learning, 2002b. . O método anticartesiano de C. S. Peirce. São Paulo: Editora Unesp, 2004.

SILVEIRA, L. F. Curso de semiótica geral. São Paulo: Quartier Latin, 2007.

SOUZA, F. Nove Chapeuzinhos. São Paulo: Companhia das Letrinhas, 2014.

\section{SOBRE O AUTOR}

André Luiz Ming Garcia é bacharel e licenciado em Letras (Universidade de São Paulo), com Mestrado e Doutorado em Letras pela mesma universidade. Tem experiência na área de literatura alemã infantil, semiótica aplicada de C. S. Peirce e questões concernentes à leitura. Desenvolve pesquisa nos seguintes temas: leitura segundo C. S. Peirce, livro ilustrado, conto de fadas. É bolsista Capes e foi bolsista de doutorado-sanduíche na Universidade de Tübingen na Alemanha. E-mail: andrelunar@gmail.com.

Recebido em 11 de março de 2017 e aprovado em 23 de julho de 2017. 